\title{
Unilateral Renal Agenesis in Chilean-Flamingo (Phoenicopterus chilensis)
}

\author{
Elton Luís Ritir Oliveira', André Luiz Mota da Costa ${ }^{2}$, Mariana Fischer Borges', \\ Viviane Christiane Nemer ${ }^{3}$, Raphael Augusto Baldissera Gonçalves ${ }^{4}$, Matheus Vasconcellos ${ }^{5}$, \\ Keylla Helena Nobre Pacifico Pereira ${ }^{6} \&$ Bruno Cesar Schimming ${ }^{7}$
}

\begin{abstract}
Background: Phoenicopterus chilensis is a South American wild bird classified as a near threatened specie in the List of Endangered Species of the International Union for Conservation of Nature. With the increase of the contact between human population and wild animals, this species' habitat is becoming increasingly vulnerable, with a declining population. Due to the importance of its conservation, the knowledge of abnormalities that affect this species becomes essential. This report aims to describe the first diagnosed case of unilateral renal agenesis in chilean-flamingo.

Case: A captive male chilean-flamingo (Phoenicopterus chilensis) was found dead in its enclosure and then was referred at necropsy. The cause of death was the presence of tracheal fungal granuloma, caused by Aspergillus sp. Macroscopically, during the examination of the body cavity, the absence of the right kidney was noted, also evidencing the absence of the caudal renal vein. Emerging from the caudal division of the kidney was noted a blind-end renal vessel. For the histopathological examination, the remaining kidney was fixed in $10 \%$ formalin, processed by paraffin embedding technique and stained with Hematoxylin and Eosin (HE). When analyzing the left kidney parenchyma, preserved histological architecture was noted, without any changes in the tissue structures of the organ. Thus, no hypertrophy by compensatory mechanisms of the remaining kidney was observed.

Discussion: Unilateral renal agenesis is a very rare congenital defect in dogs, cats and also in birds. It occurs in the complete absence of one of the kidneys, a situation with which the animal can live satisfactorily if there is a normal kidney to assume the functions. In association, ipsilateral ureteral agenesis and compensatory hypertrophy of the remaining kidney may occur. At the time of necropsy, due to the remaining kidney has normal size and within topographic limits, dorsally in contact with the pelvis and sinsacrum, the absence of compensatory hypertrophy was suspected, which was confirmed by histopathological examination. Clinical signs of unilateral renal agenesis, when present, are related to renal failure. The signs develop when the remaining kidney fails to fully absorb the other's functions and fails to maintain the organism's homeostasis. In the case of this report, the specimen showed no clinical signs related to renal agenesis, probably because was no functional compensation for the single kidney. This condition was only noticed after flamingo necropsy, who death because tracheal fungal granuloma, caused by Aspergillus $s p$. Other reported ways of diagnosing this malformation in animals while alive were imaging and abdominal cavity surgery. The etiopathogenesis of unilateral renal agenesis in animals is uncertain, however, the hereditary cause is commonly described in rats and small animals. It cannot be concluded that the same happened with the animal of this study due to the fact of lack of data regarding the parents and history of animal. It is concluded that in unilateral renal agenesis, the compensatory hypertrophy of the remaining kidney and any clinical symptoms may not be present. Necroscopic and complementary exams are essential to obtain the diagnosis of unilateral renal agenesis. Knowing that the chilean-flamingo is considered as a species near threatened of extinction, it is important to know the abnormalities that affect this species, because this information may be essential for conservation programs.
\end{abstract}

Keywords: wild animal, bird, kidney, necropsy. 


\section{INTRODUCTION}

Flamingos are large birds without sexual dimorphism. They are fresh-water and coastal birds, presenting a long neck, long and thin legs, large wings and short tail [3].

There are six species of flamingo in existence worldwide, and three of them are found in the Neotropical region. The most common specie in this region is the Chilean flamingo (Phoenicopterus chilensis) [2]. Its a native species from Chile, though it may equally be found in Peru, Bolivia, Uruguay, Paraguay, Argentina, in southern Brazil and sporadically in the Falklands [4]. This species' habitat is becoming increasingly vulnerable [5], the Chilean flamingo has declining population because of egg harvesting and habitat degradation and is classified as "near threatened" [8].

Bird's kidneys are elongated organs closely linked to the ventral part of the vertebrae; it is partially lobulated and the ureters are thick-walled ducts that open into the cloaca just above the sphincter [10]. The kidney may be affected by several abnormalities, among which we have renal agenesis, which is the absence of one or both kidneys. When bilateral, it is incompatible with life, if unilateral the patient may be asymptomatic [1].

Unilateral renal agenesis has been reported in dogs [17,13], cats [14] and common-squirrel monkey (Saimiri sciureus) [16], but this is the first time that this condition has been reported in Chilean flamingo. The purpose of this research is to report the unilateral renal agenesis in Chilean flamingo, describing the pathological characteristics about the finding.

\section{CASE}

The case refers to an adult male Chilean flamingo (Phoenicopterus chilensis) kept at Quinzinho de Barros Municipal Zoological Park, located in the municipality of Sorocaba, São Paulo State, Brazil. The bird was found dead in its enclosure and then was referred to the veterinary department.

The necroscopic examination was performed according to the traditional model for birds. Macroscopically, during the examination of the body cavity, the absence of the right kidney was noted, also evidencing the absence of the caudal renal vein, which performs its drainage. Emerging from the caudal division of the kidney was noted a blind-end renal vessel [Figure 1]. In the histopathological analysis of ex-situ organ, no hypertrophy by compensatory mechanisms of the remaining kidney was observed [Figure 2].

For the histopathological examination, the remaining kidney was fixed in $10 \%$ formalin, processed by paraffin embedding technique and stained with Hematoxylin and Eosin (HE). When analyzing the left kidney parenchyma, preserved histological architecture was noted, without any changes in the tissue structures of the organ. The presence of the normal aorta artery was observed, leading to the external iliac artery and the sciatic artery. There was the right common iliac vein, but not originated the caudal renal vein. The right ureter was present but was emitted by the cranial division of the left kidney [Figure 1].

The cause of death was the presence of tracheal fungal granuloma, caused by Aspergillus sp. This disease was not related to the absence of kidney in the animal.

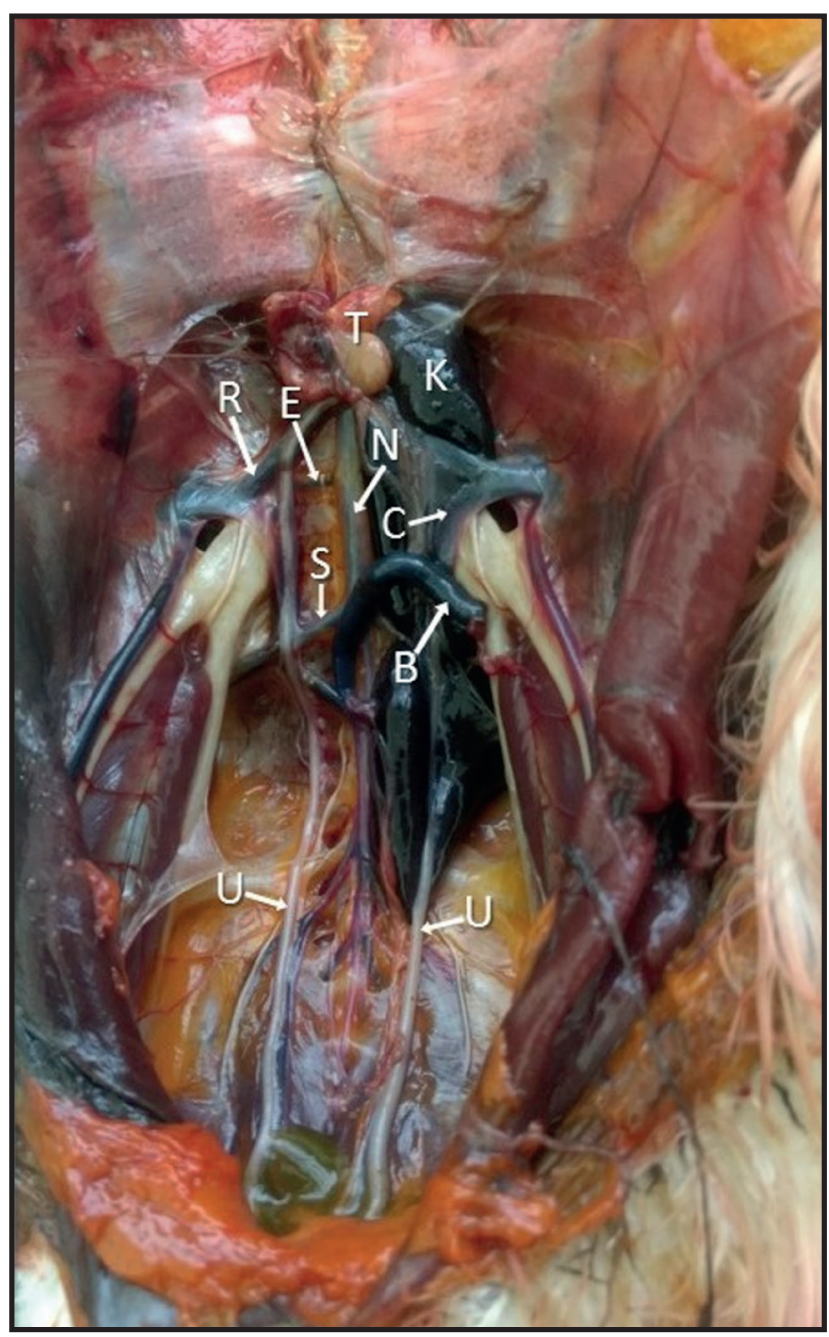

Figure 1. Body cavity of Chilean-flamingo (Phoenicopterus chilensis) showing the absence of the right kidney. U: ureter; $\mathrm{C}$ : caudal renal vein; R: right common iliac vein; S: sciatic artery; E: external iliac artery; N: normal aorta artery; K: kidney; T: testicle. 


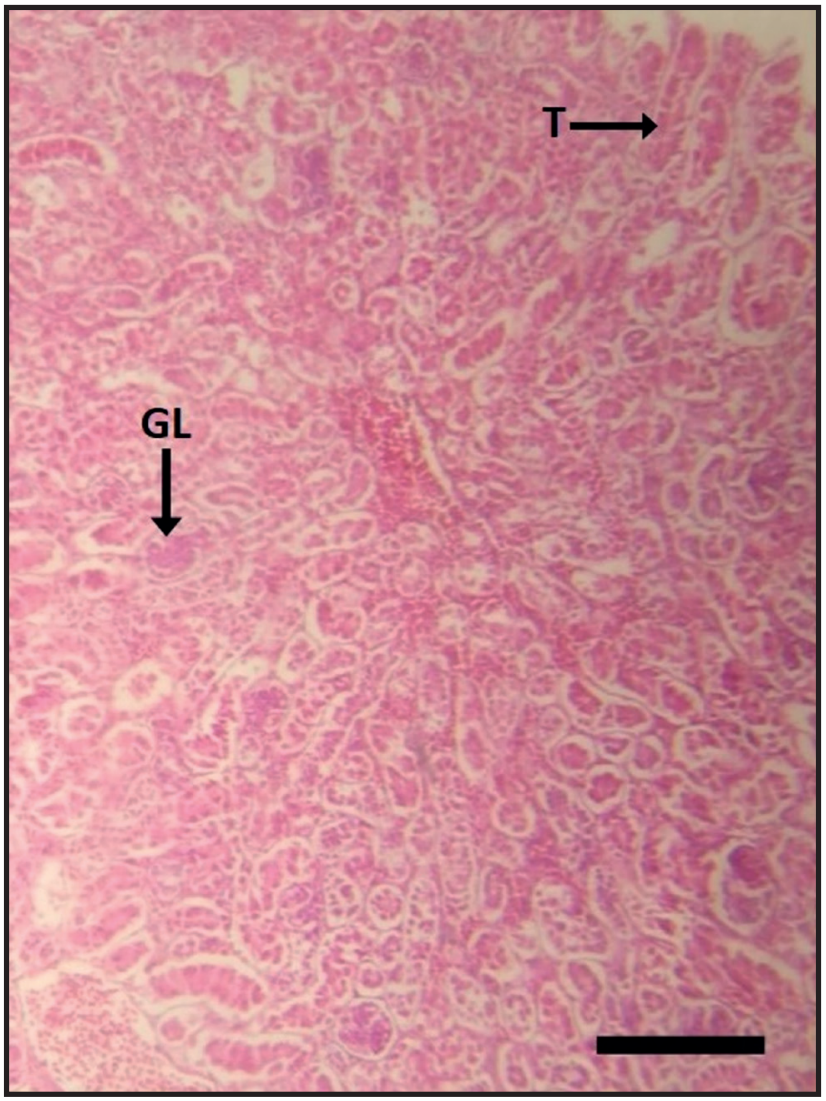

Figure 2. Histological section of chilean-flamingo (Phoenicopterus chilensis) kidney showing standard renal tissue within histological normality. GL: glomerulus; T: tubule. [H\&E; bar $=200 \mu \mathrm{m}]$.

\section{DISCUSSION}

In humans, kidney abnormalities occur more frequently than any other organ and account for about $40 \%$ of all pathological renal lesions [7]. Although the numbers are not available for birds, congenital kidney abnormalities are much less common and only hypoplasia and agenesis have been reported [15].

Unilateral renal agenesis is a very rare congenital defect in small animals. It occurs in the complete absence of one of the kidneys, a situation with which the animal can live satisfactorily if there is a normal kidney to assume the functions. In association, ipsilateral ureteral agenesis and compensatory hypertrophy of the remaining kidney may occur [6]. At the time of necropsy, due to the remaining kidney has normal size and within topographic limits, dorsally in contact with the pelvis and sinsacrum, the absence of compensatory hypertrophy was suspected, which was confirmed by histopathological examination. Besides the non-hypertrophy of the remaining kidney, it was observed in this case, that the missing kidney ureter was also connected to the remaining kidney.

In rats [11] and in domestic chickens [9] the hereditary nature of this malformation is unquestionable. It cannot be concluded that the same happened with the animal of this study due to the fact of lack of data regarding the parents.

Clinical signs of unilateral renal agenesis, when present, are related to renal failure. The signs develop when the remaining kidney fails to fully absorb the other's functions and fails to maintain the organism's homeostasis [1]. In the case of this report, the specimen showed no clinical signs related to renal agenesis, probably because was no functional compensation for the single kidney. However, there are report of absence of clinical signs of unilateral renal agenesis in a cat with functional compensation for the remaining kidney [14].

This condition was only noticed after flamingo necropsy, who death because tracheal fungal granuloma, caused by Aspergillus sp. In one report of common-squirrel monkey, unilateral renal agenesis was also identified after necropsy, since the animal which also showed no clinical signs for this condition [16]. Other reported ways of diagnosing this malformation in animals while alive were imaging [14,17] and abdominal cavity surgery [12].

It is concluded that in unilateral renal agenesis, the compensatory hypertrophy of the remaining kidney and any clinical symptoms may not be present. Necroscopic and complementary exams are essential to obtain the diagnosis of unilateral renal agenesis. This finding is importat for conservation studies in this species.

Declaration of interest. The authors report no conflicts of interest. The authors alone are responsible for the content and writing of the paper.

\section{REFERENCES}

1 Bernstein M., Bernstein K.K., Britto L.M.P. \& Loli P.A. 2009. Agenesia renal unilateral em um cão: relato de caso. Revista Científica de Medicina Veterinária de Pequenos Animais e Animais de Estimação. 7: 140-142.

2 Brandolin G. \& Ávalos M. 2010. Nuevos registros estivales de flamenco andino Phoenicoparrus andinus para la llanura central de Argentina, Provincia de Córdoba. Cotinga. 32: 5-7. 
3 Cubas Z.S., Silva J.C.R. \& Catão-dias J.L. 2014. Tratado de Animais Selvagens. 2.ed. São Paulo: Roca, 457p.

4 Del Hoyo V. 1992. Order Phoenicopteriformes, Family Phoenicopteridae (flamingos). In: Del Hoyo V., Elliot A. \& Sargatai V. (Eds). Handbook of the Birds of the World. Barcelona: Lynx Edicions, 696p.

5 Farrell M.A., Barry E. \& Marples N. 2000. Breeding behavior in a flock of Chilean flamingos (Phoenicopterus chilensis) at Dublin zoo. Zoo Biology. 19(4): 227-237.

6 Fedalto V. 2012. Agenesia renal em cão: relato de caso. [Fonte:https://www.equalis.com.br/arquivos_fck_editor/ tcc_vanessafedalto.pdf]. [Accessed online in May 2019].

7 Gorvoy J.D., Smulewicz J. \& Rothfeld S.H. 1962. Unilateral renal agenesis in two siblings. Pediatrics. 29: 270-272.

8 IUCN. 2018. BirdLife International. Phoenicopterus chilensis. The IUCN Red List of Threatened Species: e.T22697365A132068236. [Fonte:http://dx.doi.org/10.2305/IUCN.UK.2018-2.RLTS.T22697365A132068236.en]. [Accessed online in July 2019].

9 Jeffrey F.P., Beaudette E.R. \& Hudson C.B. 1937. An inherited kidney abnormality in the domestic fowl. Journal of Heredity. 28: 335-338.

10 Mayrs E.B. 1924. Secretion as a factor in elimination by the bird's kidney. The Journal of Physiology. 58(4): 276-287.

11 Morgan W.C. 1953. Inherited congenital kidney absence in an inbred strain of rats. Anatomical Record. 115: 635-639.

12 Narasimhan T. \& Absar Y. 2010. Incidental finding of renal agenesis in a cat. [Fonte:http://veterinarymedicine. dvm360.com/vetmed/Feline+Center/Incidenta-finding-of-renal-agenesis-in acat/ArticleStandard/Article/detail/673419] . [Accessed online in January 2019].

13 Pereira K.H.N.P., Burini C.H.P., Oliveira E.L.R., Canuto L.E.F., Correia L.E.C.S., Lopes M.D., Rocha N.S., Chiacchio S.B. \& Lourenço M.L.G. 2019. Hypoplasia of ribs associated with cleft palate, cleft lip, and unilateral renal agenesis in a neonate dog of undefined breed. Semina: Ciências Agrárias. 40(1): 497-502.

14 Santos E.R.D., Rosa N.S., Barni B.D.S., Oliveira M.P., Camargo V.M.F. \& Contesini E.A. 2015. Agenesia renal unilateral e criptorquidismo ipsilateral em um felino: relato de caso. Arquivo Brasileiro de Medicina Veterinária e Zootecnia. 67(2): 400-404.

15 Siller W.G. 1981. Renal pathology of the fowl - a review. Avian Pathology. 10(3): 187-262.

16 Souza N.F., Mendes C.C.R., Vasconcelos L.D.P., Carvalho F.M., Farias A.A. \& Cardoso A.M.C. 2013. Agenesia renal unilateral em Saimiri sciureus: relato de caso. In: II Congresso Brasileiro de Patologia Veterinária/XVI Encontro Nacional de Patologia Veterinária (Curitiba, Brazil). p.392.

17 Taney K.G., Moore K.W., Carro T. \& Spencer C. 2003. Bilateral ectopic ureters in a male dog with unilateral renal agenesis. Journal of the American Veterinary Medical Association. 223(6): 817-820. 